\title{
The role of personal relationships in supply chain risk information sharing: Perspectives from buyers and suppliers of logistics services
}

\begin{tabular}{|c|c|}
\hline \multicolumn{2}{|c|}{$\begin{array}{l}\text { Authors: } \\
\text { Marco van der Walt }{ }^{1} \\
\text { Wesley Niemann } \\
\text { Arno Meyer } \\
\text { A }\end{array}$} \\
\hline \multicolumn{2}{|c|}{$\begin{array}{l}\text { Affiliations: } \\
\text { 'Department of Business } \\
\text { Management, Faculty of } \\
\text { Economic and Management } \\
\text { Sciences, University of } \\
\text { Pretoria, Pretoria, } \\
\text { South Africa }\end{array}$} \\
\hline \multicolumn{2}{|c|}{$\begin{array}{l}\text { Corresponding author: } \\
\text { Wesley Niemann, } \\
\text { wesley.niemann@up.ac.za }\end{array}$} \\
\hline \multicolumn{2}{|c|}{$\begin{array}{l}\text { Dates: } \\
\text { Received: } 13 \text { May } 2020 \\
\text { Accepted: } 28 \text { May } 2021 \\
\text { Published: } 30 \text { July } 2021\end{array}$} \\
\hline \multicolumn{2}{|c|}{$\begin{array}{l}\text { How to cite this article: } \\
\text { Van Der Walt, M., Niemann, } \\
\text { W. \& Meyer, A., 2021, 'The } \\
\text { role of personal relationships } \\
\text { in supply chain risk } \\
\text { information sharing: } \\
\text { Perspectives from buyers and } \\
\text { suppliers of logistics services', } \\
\text { South African Journal of } \\
\text { Economic and Management } \\
\text { Sciences } 24(1), \text { a3703. } \\
\text { https://doi.org/10.4102/ } \\
\text { sajems.v24i1.3703 }\end{array}$} \\
\hline \multicolumn{2}{|c|}{$\begin{array}{l}\text { Copyright: } \\
\text { (c) 2021. The Authors. } \\
\text { Licensee: AOSIS. This work } \\
\text { is licensed under the } \\
\text { Creative Commons } \\
\text { Attribution License. }\end{array}$} \\
\hline \multicolumn{2}{|l|}{ Read online: } \\
\hline 口, & $\begin{array}{l}\text { Scan this QR } \\
\text { code with your } \\
\text { smart phone or } \\
\text { mobile device } \\
\text { to read online. }\end{array}$ \\
\hline
\end{tabular}

Background: The frequent occurrence of supply chain disruptions highlights the importance of sharing supply chain risk information (SCRI) among buyers and suppliers in third-party logistics (3PL) services. Business relationships and long-term collaboration among supply chain partners (SCP), such as 3PLs and their clients, lead to the sharing of SCRI. Risk information sharing (RIS) cannot be effectively carried out unless these relationships are based on more than just transactional information sharing. Therefore, a better understanding is needed of how personal relationships influence RIS among these partners.

Aim: The purpose of this study was to explore the role of personal relationships in supply chain RIS from the perspective of buyers and suppliers in 3PL services in South Africa.

Setting: The study was conducted among buyers and suppliers in 3PL services in South Africa.

Method: A generic qualitative research approach was followed to conduct 18 semi-structured interviews with senior managers, employed by buyers and suppliers of 3PL services.

Findings: A personal relationship among buyers and suppliers of logistics services is the cornerstone to ensure that risk information is shared effectively. Accountability, reliability, and approachability are the main behavioural attributes required to ensure RIS among SCPs. Supply chain partners struggle to determine where the boundaries of a personal relationship lie, especially when risk information is shared. The most common mitigation strategies, when dealing with RIS, are the use of a code of conduct, a code of ethics and a standard nondisclosure agreement (NDA).

Conclusion: The study provides insight into the role of personal relationships in supply chain RIS, the behavioural attributes required for RIS, and the challenges associated with RIS when a personal relationship is present. The study is, arguably, among the first empirical studies in the South African logistics services context to investigate the role of personal relationships in supply chain RIS.

Keywords: personal relationships; risk information sharing; supply chain risk mitigation; qualitative research; South Africa.

\section{Introduction}

Keith Ferrazzi, a New York Times best-selling author, was quoted saying: 'Power comes from sharing information, not withholding it'. Likewise, information technology (IT) innovations are shaping the modern-day supply chain and, as a result, firms and their supply chain partners (SCPs) are becoming progressively more dependent on information sharing among one another (Colicchia et al. 2018:5; Kache \& Seuring 2017:11). Today, the collection and sharing of information is faster and simpler, allowing supply chains to operate in a globally connected environment (Colicchia et al. 2018:5). South Africa is recognised as the most developed country in Africa in terms of the third-party logistics (3PL) industry. As a result, the majority of logistics activities on the continent are performed by South African 3PL service providers (Nel, De Goede \& Niemann 2018:2). The utilisation of 3PL service providers creates a network among buyers and suppliers for potential information sharing and risk mitigation (Huong Tran, Childerhouse \& Deakins 2016:1103). The purpose of sharing information is to ensure real-time information processing and decision-making between the firm and its 3PLs (Prajogo \& Olhager 2012:514-516). Third-party logistics partners can provide timely feedback, outsource processes and track service activities by sharing information (Zacharia, Sanders \& Nix 2011:43-44). Information sharing enables firms to experience improved resilience and increased supply chain visibility (Brandon-Jones et al. 2014:56-57). 
Information sharing between 3PL partners may lead to risk exposure (Colicchia et al. 2018:6). These potential risks typically include the risk of leaking business secrets, losing bargaining power with the SCP and information security (Qi \& Zhang 2008:3). Risk information sharing, supply chain resilience, and risk mitigation facilitate a firm's ability to anticipate and manage emerging threats (Ambulkar, Blackhurst \& Grawe 2015:111-112).The successful mitigation of supply chain risk (SCR) requires a strong relationship with a firm's 3PLs (Langley \& Long 2012:26). Supply chain RIS is the degree to which both priority and critical information are shared with a firm's SCPs (Li et al. 2015:84-85). Prior investigations predominantly focused on the collection and processing of risk information, as opposed to RIS (Liao, Yuan \& McComas 2018:911).

Supply chain risk is significantly influenced by supply chain integration (Jüttner \& Maklan 2011:253). Effective departmental integration reduces uncertainty, while improving visibility, as increased visibility and reduced uncertainty lead to improved SCR management ( $\mathrm{Li}$ et al. 2015:84; Liu \& Lee 2018:8). Supply chain risk may reduce, either directly or indirectly, after 3PL integration into the supply chain (Jüttner \& Maklan 2011:253; Liu \& Lee 2018:8-9). Operational integration and the sharing of risk information among firms and their external partners improve a firm's SCR mitigation (Wieland \& Wallenburg 2013:306). Successful mitigation of SCR requires a strong relationship with a firm's 3PLs and clients (Langley \& Long 2012:26). Risk information sharing enables a firm to build stronger relationships and promote integration between the various SCPs, resulting in improved performance (Khan, Hussain \& Saber 2016:213; Liu \& Lee 2018:17). By integrating IT, RIS can be done more effectively, reducing incidences of conflict among various functional areas, internally, as well as externally (Liu \& Lee 2018:15).

Research investigating the role of personal relationships in the logistics context only recently started receiving attention (Gligor \& Holcomb 2013:336; Mocke, Niemann \& Kotzé 2016:3; Meyer, Niemann \& Kotzé 2017:1; Rood et al. 2018:1-2). Gligor and Autry (2012:26) emphasise the importance of personal relationships, as these influence the communication of information, establishing a steady link between personal relationships and the enhanced communication of information. Current research investigates the sharing of information (Eckerd \& Sweeney 2018:413), and the impact of sharing SCR information (SCRI) on relationship resilience (Durach \& Machuca 2018:1868). Liao et al. (2018:930) call for further research on the role of personal relationships in RIS. Additional research is necessary in the 3PL context, as information sharing, and especially RIS, may lead to the exposure of unique information risks and practices, due to the nature of the outsourcing relationship (Colicchia et al. 2018:17; Rajagopal, Venkatesan \& Goh 2017:675).

The purpose of this qualitative study is to investigate the role of personal relationships in supply chain RIS from the perspective of buyers and suppliers in the South African 3PL context. Furthermore, in this study the required personal behavioural attributes to ensure the sharing of SCRI, as well as the challenges and the types of security risks associated with RIS, are explored, including how information-sharing risks are mitigated. In the study a generic qualitative research design is used combined with semi-structured interviews to collect data from buyers and suppliers of 3PL services in South Africa.

The following research questions guided the study:

1. What role do personal relationships play in supply chain RIS between buyers and suppliers of logistics services?

2. Which personal behavioural attributes are required to ensure supply chain RIS between buyers and suppliers?

3. What are the challenges associated with supply chain RIS when a personal relationship exists between buyers and suppliers of logistics services?

4. What are the security risks associated with supply chain RIS when a personal relationship exists between buyers and suppliers of logistics services?

5. How is RIS mitigated when a personal relationship exists between a buyer and supplier of logistics services?

The contribution of this study is threefold: firstly, it was undertaken in response to the call of Liao et al. (2018:930) for the role of personal relationships in RIS to be probed; secondly, it is one of the first empirical studies to investigate the role of personal relationships in supply chain RIS in a logistics-services context; finally, the study identifies new challenges associated with RIS.

The remainder of the article is structured as follows: firstly, a comprehensive review of current literature is provided; secondly, the methodology of the study is discussed; thereafter, the findings are presented and discussed. Finally, a discussion of the findings is followed by the limitations and future research opportunities.

\section{Literature review}

\section{The third-party logistics services industry}

The outsourcing of logistics is a growing field of business and the services provided progress from single service types to a broad range of services, together with supply chain solutions, contributing to the trend of logistics outsourcing (Karrapan et al. 2017:2). The 3PLindustry consists of specialist service providers who offer various warehousing, transport, and freight-forwarding services (Ab Talib, Abdul Hamid \& Thoo 2015:12). Major sectors, such as fast-moving consumer goods (FMCG), the pharmaceutical, IT and retail sectors, as well as the automotive industry outsource a range of logistics services to 3PLs (Karrapan et al. 2017:2).

The 3PL industry has grown exponentially in the global market through its vast range of services and activities of warehousing, IT services, order fulfilment and management, supply chain consulting and freight-forward services (Karrapan et al. 2017:1). The South African logistics industry 
contributes more than R499 billion to the economy every year. This amounts to $11.8 \%$ of the gross domestic product (GDP) which highlights the crucial role the 3PL industry plays in the South African economy (Havenga et al. 2016:3). Over the last decade 3PLs in South Africa have enabled multiple firms to integrate their supply chains, contributing to enhanced visibility and more efficiency (Mocke et al. 2016:2). Thus, the South African 3PL industry is an economic resource and acts as a significant driver in acquiring a global competitive advantage (Havenga et al. 2016:6).

\section{Personal relationships}

Personal relationships can be defined as an interpersonal bond between the managers of different firms, based on strict and formal business exchanges, and distinct from their formal business relationship (Porterfield, Macdonald \& Griffis 2012:1). Two main characteristics differentiate business and personal relationships from one another (Mocke et al. 2016:2-3). Firstly, business relationships are perceived as more instrumental, while personal relationships are more emotional and deeply rooted, as participants in business relationships are required to complete tasks in the manner prescribed by their roles (Fournier, Dobscha \& Mick 1998:45; Grayson 2007:122). Secondly, business relationships are rooted in the requirement to perform a specific task; however, personal relationships are characterised by more free and spontaneous actions (Allan 1989:20).

Unique benefits and actions evolve when a personal relationship exists between a buyer and a supplier (Gligor \& Holcomb 2013:336; Rood et al. 2018:1-2). These unique benefits include trust, enhanced personal and business understanding, improved communication and increased business volume (Gligor \& Holcomb 2013:336-343). Thirdparty logistics service relationships, rooted in a strong personal relationship, may lend a competitive advantage to both firms involved; as such, a significant relationship cannot easily be imitated (Leuschner et al. 2014:25).

The collaboration and mutual connection between individuals lead to the establishment of personal relationships and interdependence (Gligor \& Holcomb 2013:329; Rood et al. 2018:3). Performance levels of both the buyers and suppliers of logistics services may be enhanced by improved business knowledge and communication (Zhou et al. 2014:88). Personal relationships are established for two primary reasons: the first is to enhance the overall professional interest of both individuals; the second is friendship for its own sake (Meyer et al. 2017:15).

\section{Personal behavioural attributes}

To achieve effective information sharing, four attributes are required on a personal relationship level among the SCPs, namely collaboration and relationship length, trust and commitment (Li et al. 2015:91). Collaboration can be described as working towards improvement for both parties (Jin, Fawcett \& Fawcett 2013:205). Collaboration and relationship length are the most influential factors in a personal relationship to achieve that competitive advantage, because of the benefits of sharing knowledge and resources. (Vaidya \& Hudnurkar 2013:293). The basis of personal relationships is formed through effective collaboration among SCPs. This form of collaboration is not only based on quality and price, but rather on the personal relationship itself (Vermeulen, Niemann \& Kotzé 2016:6). Relationship length refers to how long partners know each other. Once a long-term relationship is established, supply chain members can identify their partners' routine as the result of frequent sharing of SCRI ( $\mathrm{Li}$ et al. 2015:86). The combination of supplier trust and relationship length can enhance the effectiveness of RIS and SCR management (Li et al. 2015:89).

Trust within a personal relationship is a professed competence, which includes consistency, confidence, fairness, goodwill, objectivity and the expectation that the partners will be supportive in their actions and not exploit one another (Van Riper et al. 2016:25). Commitment, as a personal behavioural attribute, is a promise or agreement to perform a particular task or action in future (Asif Salam 2011:360). Commitment is also seen as the continued aspiration towards strengthening and maintaining personal relationships (Asif Salam 2011:360-361). In a relational context, commitment is an arrangement among SCPs to meet predetermined agreements. Both trust and commitment are of vital importance for the improvement of supply chain efficiency, responsiveness and customer satisfaction. Trust and commitment refer to the long-term commitment by parties to meet their obligations as agreed upon (Jie, Parton \& Cox 2013:1005), suggesting that to achieve successful sharing of risk information, a personal relationship is required. The relationship should focus on the development of trust and commitment in this context (Du et al. 2012:96).

Finally, trust influences social interaction among SCPs and the quality of the personal relationship positively (Barnes et al. 2015:27; Skinner, Dietz \& Weibel 2014:206-207; Wang et al. 2016:841). The degree of complexity, uncertainty, power asymmetry and dependency all influence the level of trust among SCPs (Lavastre, Gunasekaran \& Spalanzani 2014:3387; Wang et al. 2016:842). Once these partners share similar characteristics, trust is established, and as the degree of transparency and honesty increases, the level of trust is raised (Gligor \& Holcomb 2013:330).

\section{Supply chain information sharing}

Supply chain information sharing is the degree to which proprietary and critical information are communicated to SCPs (Huong Tran et al. 2016:1103). The sharing of information can take place in two ways: externally, information is shared with partners in the firm's supply chain to enhance financial work processes, the physical flow and demand planning; internally, information is shared to ensure company growth and effective purchase planning, resulting in improved coordination and flexibility (Du et al. 2012:89). A firm's willingness to share information in the 
supply chain context is seen as a trade-off between the firm's responsiveness to information resources and its efficiency in sharing information. The type of information being shared depends on the technology available; however, the question of when and with whom information is shared means that social involvement should be taken into consideration (Prajogo \& Olhager 2012:519-520). Social involvement in the supply chain context refers to informal partnerships formed among buyers, suppliers and other service providers.

Traditional supply chain management investigations focused predominantly on the operational components by emphasising the efficiency of the product and service flow (Du et al. 2012:90). In recent times, greater emphasis has been placed on relationship development and performance in the supply chain. These relationships are treated as a range extending from strategic to independent relationships, depending on the level of interdependence, strategic goals, and exclusivity (Prajogo \& Olhager 2012:514).

\section{Supply chain risk information sharing}

When a firm implements RIS, the firm and its SCPs agree to exchange SCR-related information with one another in an accurate and timely manner. Supply chain RIS refers to communication beyond the standard exchange of business information about the possibility of unexpected events causing disruptions in the firm's supply chain (Ali, Hird \& Whitfield 2018:3). The execution of the process is a critical element, which leads to enhanced supply chain visibility and a culture of information sharing (Li et al. 2015:84). Establishing a culture of RIS among SCPs is the first step towards SCR management. A strong link must be evident between the validity of the shared information and the success of managing the SCR (Fan et al. 2017:71). A RIS culture is an essential part in the relationship between firms and their suppliers in developing a dependable channel of communication. Risk information sharing has a positive impact on the firms' supply chain practices, such as just-intime production, planning, and delivery (Ali et al. 2018:3).

Risk information sharing is also capable of facilitating the integration of the firms' logistics by maintaining a consistent flow of inventory and materials between the firm and its suppliers (Kim \& Chai 2017:45). With improved collaboration and integration in the supply chain, RIS can increase the firms' flexibility and their speed to respond and accommodate various preferences in demand ( $\mathrm{Li}$ et al. 2015:89). This is all made possible by the frequent RIS between a firm and its suppliers (Kim \& Chai 2017:45). Firms that form part of a personal relationship network might be more willing to share riskrelated information among SCPs (Ali et al. 2018:3; Nahapiet \& Ghoshal 1998:250). Therefore, firms feel obliged to share riskrelated information among partners on the strength of their personal relationships and the degree of their closeness (Ali et al. 2018:6; Nahapiet \& Ghoshal 1998:250).

Establishing a sense of communal value among SCPs improves the sharing of SCRI, as the partners become more concerned, not only about maintaining an existing relationship, but also about the welfare of both parties (Ali et al. 2018:8). Hence, personal relationships can improve understanding among SCPs regarding risk events, because a disruption in a partner's operation can negatively affect the entire supply chain function.

\section{Challenges associated with risk information sharing}

Although RIS is used to reduce supply chain complexity and challenges, it comes with its own set of challenges. The most common challenges associated with RIS is the lack of trust among SCPs, because if you do not trust your partner you are not going to share risk information with them. Furthermore, the lack of SCP commitment is a challenge experienced by partners when risk information is shared, which could lead to inconsistency in supply and fluctuations in customer demand (Huong Tran et al. 2016:1114). While RIS has the possibility of enhancing supply chain visibility, firms might experience RIS as a threat to their survival (Jüttner \& Maklan 2011:254). Convincing SCPs to share risk information is a challenge as it is, as it increases a firm's vulnerability in its efforts to support SCR management decisions and practices (Li et al. 2015:84). This vulnerability increases as a result of increased supply chain complexities (Bode \& Wagner 2015:216; Habermann, Blackhurst \& Metcalf 2015:493). Without the required visibility, the possibility of uncertainty arising among SCPs is increased, which could lead to supply chain inefficiency (Kurniawan et al. 2017:8).

\section{Security risk associated with risk information sharing}

The risk associated with RIS in the supply chain requires rigorous investigation (Du et al. 2012:97; Wang, Ye \& Tan 2014:7). Such risk includes the leakage of private information, both internally and across the supply chain, and the degrading of the quality of information (Madenas et al. 2015:1160). Both the intentional and unintentional disclosure of confidential information to unauthorised parties pose a security risk (Tan, Wong \& Chung 2016:622). Direct disclosure refers to sharing confidential information, while indirect disclosure is the disclosure of sensitive information, mistakenly identified as non-confidential information, and thus shared among partners in personal relationships (Zhang et al. 2012:1355). However, the loss of intellectual property is perceived as the greatest of risks when sharing SCRI (Huong Tran et al. 2016:1119).

Another critical security risk associated with RIS is information leakages (Colicchia et al. 2018:14). This is seen as a vital point, as complexity is reflected by the operational structure and mechanisms in the modern-day supply chains (Colicchia et al. 2018:16). Risk information sharing enables firms to survive in a dynamic and volatile working environment (Barnes et al. 2015:26). Personal relationships are renowned for informal conversations, and the sharing of sensitive information during these conversations, which might be misused for personal gain (Gligor \& Holcomb 2013:339). As the line between right and wrong fades, SCPs become all the more aware of the leaking of sensitive SCRI and how the leaking thereof could have major legal implications (Rood et al. 2018:11). 


\section{Information sharing risk mitigation strategies}

Lavastre et al. (2014:3396) identified two strategies for mitigating the information sharing risk, namely the management of the information flow and monitoring the relationships and risks. Information flow consists of eight subcategories, namely: (1) the truthful exchange of forecasts regarding future demands and future events; (2) an efficient communication and information exchange to prevent any type of miscommunication; (3) appointing a risk manager who specialises in supply chain management; (4) participating with key partners in the proactive exchange and cooperation of forecasts; (5) ensuring centralised decision-making on all levels of communication for a holistic alignment; (6) making sure that supply chain management is responsive and reactive to change in information; (7) implementing an advanced planning system to conduct activity planning; and finally (8) implementing collaborative information systems to ensure that all functions communicate clearly with one another at all times. The second strategy is to monitor relationships and risks. The subcategories include: (1) developing indicators to measure SCR management effectiveness, as this will provide firms with the ability to identify which risk management approaches are working and which are not; (2) developing indicators to monitor the risk related to specific partners, as this will enable the firm to address partner-specific risks as they are identified; and finally (3) developing a set of indicators to monitor and evaluate possible risks without the attendance of the SCP (Lavastre et al. 2014:3396).

Furthermore, SCPs may agree to a code of conduct and ethics. The compliance of suppliers to a code of conduct will increase once the personal relationship among multi-principal collaborators and 3PLs is governed by a behaviour-based contract, linked to monitoring protocol (Delbufalo \& Bastl 2018:1245). Compliance with the code of conduct will increase when information sharing between multi-principal collaborators is administrated by a formal and informal control mechanism (Delbufalo \& Bastl 2018:1248). In order to assure effective management of RIS, both the code of conduct and the code of ethics must be implemented. Under the code of ethics, firms are required to establish standards in order to promote ethical and honest conduct, such as the handling of actual conflicts of interest, due to the existence of a personal relationship (Banks 2010:341). Firms must adequately communicate the code of ethics and ethical guidelines to all of its employees (Banks 2010:352). Within the service agreement, a firm will require the client to provide access to their system purely for operational purposes, through the signing of an NDA (Horák, Stupka \& Husák 2019:6).

\section{Methodology \\ Research design}

In this study a generic qualitative research design is employed. Generic qualitative research was appropriate because the researchers possessed some prior knowledge of the specific phenomenon under investigation and wished to fully describe the topic from the perspectives of participants (Percy, Kostere \& Kostere 2015:78). This design enabled the researchers to obtain a better understanding of the role of personal relationships in the supply chain RIS, from the perspectives of 3PL buyers and suppliers (Cooper \& Schindler 2014:161). Cross-sectional primary data were gathered by conducting semi-structured interviews with 3PL buyer and supplier firms in South Africa.

\section{Sampling}

The unit of analysis in the study was the personal relationship between a buyer and a supplier of logistics services in South Africa. The units of observation in the study were the individual participants employed at either the buyer or the supplier firm. The final sample size was based on the principle of data saturation (Guest, Bunce \& Johnson 2006:74). The study included 18 participants of which nine represented 3PL firms and the remaining nine 3PL clients. In this study, all the codes were identified after the 12th interview and the main themes were identified. An additional six interviews were conducted without any new significant data being presented.

Homogeneous sampling, a form of purposive sampling was used in the study. This entails the deliberate selection of firms and individuals based on distinct similarities (Creswell 2012:208). The 3PL firms were sampled first, followed by the client firms that met the inclusion criteria. The direct client firms that complied with the inclusion criteria were then determined, using snowball sampling. The 3PL and client firms needed to meet the following inclusion criteria: firstly, 3PL and client firms must have an existing buyer-supplier business relationship of a minimum of two-year duration, guided by a contractual agreement. The two-year duration provided a reasonable amount of time for a relationship to be established. Secondly, the firm needed to be based in South Africa and operate here.

Participants from 3PL and client firms had to meet the following inclusion criteria. Firstly, participants needed to be in a middle or senior management position, as this ensured that participants had experience in their field and would make a valuable contribution to the study. Secondly, the participant had to be engaged in a personal relationship with a staff member of the client or 3PL. The purpose of the interaction was to ensure a direct link between the two firms. Thirdly, the participants needed to have a minimum of two years' experience in the firm, as this is generally the time it takes employees to familiarise themselves with the operations of a firm (Oakes 2012:40). Snowball sampling of participants was initiated once the data collection process started and it made sense to use referrals, as potential participants could be identified by existing participants (Creswell 2012:206-209; Polit \& Beck 2012:517-520). Table 1 provides a profile of the participants included in the study.

\section{Data collection}

Semi-structured interviews were held to collect data. These interviews were conducted to understand the experiences 
TABLE 1: Profile of study participants.

\begin{tabular}{llllc}
\hline $\begin{array}{l}\text { Participant } \\
\text { code }\end{array}$ & Job title & Gender & $\begin{array}{c}\text { Years at } \\
\text { firm }\end{array}$ & $\begin{array}{c}\text { Duration of } \\
\text { interview } \\
\text { (minutes) }\end{array}$ \\
\hline Buyers of logistics services (Client firms) & & & & \\
B1 & Inbound logistics manager & Female & 3 & 28 \\
B2 & Transport operations manager & Female & 8 & 17 \\
B3 & National logistics manager & Male & 4.5 & 19 \\
B4 & Head of supply chain and strategic & Female & 8 & 32 \\
& Sourcing & Male & 11 & 23 \\
B5 & Operation manager & Male & 17 & 24 \\
B6 & District assistant manager & Female & 7 & 34 \\
B7 & Non-executive logistics manager & Male & 28 & 23 \\
B8 & Logistics director & Male & 6 & 15 \\
B9 & National equipment and risk & & & \\
& manager & & & \\
Suppliers of logistics services (3PL firms) & Transport operations manager & Male & 23 & 27 \\
S1 & Regional executive & Male & 4 & 26 \\
S2 & Managing director & Male & 3.5 & 29 \\
S3 & Business development executive & Male & 15 & 26 \\
S4 & Director of operations and solutions & Male & 13 & 19 \\
S5 & National customs manager & Male & 15 & 40 \\
S6 & Contract logistics manager & Male & 5.5 & 17 \\
S7 & Senior outbound manager & Male & 2 & 23 \\
S8 & warehousing manager & Male & 6 & 24 \\
S9 & & & \\
\hline & & & & \\
\hline
\end{tabular}

and perceptions of participants (Myers 2013:5). This data collection method enabled the researcher to ask open-ended questions with the help of a discussion guide developed from literature. Guided by the questions, the participants were able to reflect on their own perspectives and beliefs (Cachia \& Millward 2011:268-269; Sandelowski 2000:338). A preliminary test was conducted with a participant who complied with the inclusion criteria. Minor adjustments were made to the discussion guide; however, the participant was not included in the final sample of the main study. Eighteen participants were interviewed face-to-face on a one-on-one basis. Interviews were conducted at the respective offices of the participants during September 2019. The researchers transcribed the audio interview recordings. The accuracy of transcripts was ensured by checking the completed transcript against the interview recordings.

\section{Data analysis}

Thematic analysis was used to analyse the data. It entails a systematic process of identifying codes, grouping the codes, and then organising the codes into themes and subthemes (Creswell \& Plano Clark 2015:289). ATLAS.ti version 8 was used. An a priori code list was derived from literature. The researchers listened to the audio recordings to familiarise them with both repeated and new responses in order to derive codes. The existing code list was continuously updated every time a new code was generated.

\section{Trustworthiness}

A four-criterion framework, consisting of credibility, dependability, confirmability, and transferability, was used to ensure the trustworthiness of the findings (Polit \& Beck 2012:583). Firstly, the credibility of the study refers to the accuracy of the findings compared to the study's aim and how well the participants' actual perspectives are represented in the findings (Lietz \& Zayas 2010:191-192; Polit \& Beck 2012:584-585; Shenton 2004:64-68). Credibility was obtained by using site triangulation. This entails recruiting each participant from a unique firm to prevent the themes identified from being exclusive to a particular firm (Shenton 2004:65). Secondly, dependability refers to the reliability and stability of data under certain conditions and over time. It includes the likelihood of finding similar results if the proposed research study was to be replicated by another researcher under similar conditions and with similar methods and participants (Polit \& Beck 2012:585). Through a thorough and comprehensive description of the methodology, the dependability of the study is demonstrated (Lietz \& Zayas 2010:95).

Thirdly, the study should be a true reflection of the participants' experiences and not those of the researcher (Polit \& Beck 2012:585; Shenton 2004:72). A link between the data collected and the study's reference literature was made by conducting a thematic data analysis where the main themes and sub-themes where identified to ensure that the true ideas and experiences of the participants are reflected and not those of the researcher (Lietz \& Zayas 2010:197; Polit \& Beck 2012:584-585; Shenton 2004:72), thus attaining confirmability. Finally, transferability represents the extent to which the findings of the research study can be applied to different groups, settings or contexts (Polit \& Beck 2012:585). Transferability was achieved through the provision of a detailed description of the participants, the length and number of the interviews conducted, the data collection methods employed, as well as the findings and limitations of the study (Elo et al. 2014:6; Shenton 2004:70).

\section{Ethical considerations}

The relevant Research Ethics Committee at the University of Pretoria approved the study. All participants in the study were required to read and sign an informed consent form before the interview was conducted. The informed consent form clearly explained the purpose of the study, that participation was voluntary, that the participant could withdraw at any time, and assured them of their confidentiality and anonymity. Aliases were used in the transcripts and the final presentation of data instead of the names of the participating firms and participants. The study's findings are presented in the next section.

\section{Findings}

Five main themes were identified from the data, namely the role of personal relationships in RIS, the behavioural attributes required for RIS, the challenges associated with RIS, the security risks associated with RIS and the risk mitigation of information sharing. Each of the themes was 
examined and supported by quotations from the participants. The sections that follow discuss each of the identified themes, highlighting the most significant views in each theme, as mentioned by participants.

\section{Theme 1: The role of personal relationships in risk information sharing}

Participants emphasised the primary role of a personal relationship among 3PLs and client firms in relation to RIS, as seen in Table 2 .

Participants indicated that the role of a personal relationship is to build trust among SCPs; thus, when trust is present, SCPs are more willing to share risk information and confidential information with one another as supported by the following quotation:

'You're able to gain their trust on that person and you then are able to express more confidential information.' (P18, male, customer service parts and warehousing manager)

This finding is in alignment with literature as the establishment of a personal relationship enhances trust among SCPs (Gligor \& Holcomb 2013:336-343).

Several participants indicated that a personal relationship promotes openness among buyers and suppliers. As a result of not feeling restricted, SCPs are more open to sharing SCRI with one another. This expands on current literature and is supported by the following quotation:
'Because if you do have that kind of relationship, that's going to be a lot easier to talk about stuff that you shouldn't be talking about. Um, well, sharing information when you have an open friendly relationship is differently risky.' (P10, male, district assistant manager)

The closer the personal relationship among SCPs, the greater the willingness to share risk information with one another as indicated by participants. This is the benefit of a personal relationship. The following quotation clearly illustrates this point:

'The better my relationships with my 3PL management, the more willing they are to divulge what's actually going on.' (P2, female, transport operations manager)

Participants indicated that in order to share risk information more freely with SCPs, a long-term personal relationship must first be established. The longevity of the personal relationship may ensure the sharing of risk information on a regular basis, as seen in the following quotation:

'It's just the extent of that ... that relationship, which becomes important.' (P6, male, managing director)

The findings regarding the willingness to share risk information and the longevity of a personal relationship are in alignment with those in current literature as the existence of a close personal relationship increases the willingness to share risk information with SCPs (Gligor \& Esmark 2015:519).

TABLE 2: Frequencies of the role of personal relationship in risk information sharing.

\begin{tabular}{|c|c|c|c|c|c|c|c|c|c|c|c|c|c|c|c|c|c|c|c|}
\hline \multirow[t]{2}{*}{ Sub-themes } & \multicolumn{19}{|c|}{ Participants } \\
\hline & 1 & 2 & 3 & 4 & 5 & 6 & 7 & 8 & 9 & 10 & 11 & 12 & 13 & 14 & 15 & 16 & 17 & 18 & Total \\
\hline $\begin{array}{l}\text { Enhancing the degree of trust } \\
\text { between buyer and supplier }\end{array}$ & $\checkmark$ & $\checkmark$ & $\checkmark$ & $\checkmark$ & - & $\checkmark$ & $\checkmark$ & $\checkmark$ & $\checkmark$ & - & - & $\checkmark$ & $\checkmark$ & - & $\checkmark$ & $\checkmark$ & - & $\checkmark$ & 13 \\
\hline $\begin{array}{l}\text { Enhancing the degree of } \\
\text { openness between buyer and } \\
\text { supplier }\end{array}$ & $\checkmark$ & $\checkmark$ & $\checkmark$ & $\checkmark$ & - & - & $\checkmark$ & $\checkmark$ & - & $\checkmark$ & $\checkmark$ & - & $\checkmark$ & - & - & $\checkmark$ & - & $\checkmark$ & 11 \\
\hline $\begin{array}{l}\text { Enhancing the willingness to } \\
\text { share risk information }\end{array}$ & $\checkmark$ & $\checkmark$ & $\checkmark$ & $\checkmark$ & - & - & $\checkmark$ & - & - & $\checkmark$ & $\checkmark$ & $\checkmark$ & - & - & $\checkmark$ & - & $\checkmark$ & $\checkmark$ & 11 \\
\hline $\begin{array}{l}\text { Contributing to the longevity of } \\
\text { the relationship between buyer } \\
\text { and supplier }\end{array}$ & $\checkmark$ & - & $\checkmark$ & - & - & $\checkmark$ & $\checkmark$ & - & $\checkmark$ & - & $\checkmark$ & - & $\checkmark$ & $\checkmark$ & - & $\checkmark$ & $\checkmark$ & - & 10 \\
\hline $\begin{array}{l}\text { Enhancing the degree of } \\
\text { collaboration between buyer } \\
\text { and supplier }\end{array}$ & - & - & - & $\checkmark$ & - & - & $\checkmark$ & $\checkmark$ & - & - & $\checkmark$ & $\checkmark$ & $\checkmark$ & - & - & $\checkmark$ & $\checkmark$ & $\checkmark$ & 9 \\
\hline $\begin{array}{l}\text { Enhancing the degree of } \\
\text { comfort between buyer and } \\
\text { supplier }\end{array}$ & - & $\checkmark$ & $\checkmark$ & - & - & $\checkmark$ & $\checkmark$ & $\checkmark$ & - & $\checkmark$ & $\checkmark$ & - & - & - & - & $\checkmark$ & - & $\checkmark$ & 9 \\
\hline $\begin{array}{l}\text { Ensuring the sharing of similar } \\
\text { values }\end{array}$ & $\checkmark$ & - & - & $\checkmark$ & - & $\checkmark$ & $\checkmark$ & - & - & - & - & - & - & $\checkmark$ & - & $\checkmark$ & - & $\checkmark$ & 7 \\
\hline $\begin{array}{l}\text { Enhancing the degree of } \\
\text { understanding of each other's } \\
\text { operations }\end{array}$ & $\checkmark$ & - & - & - & - & $\checkmark$ & - & - & $\checkmark$ & - & $\checkmark$ & - & $\checkmark$ & - & - & - & $\checkmark$ & - & 6 \\
\hline $\begin{array}{l}\text { Representing the cornerstone } \\
\text { to RIS }\end{array}$ & $\checkmark$ & - & - & $\checkmark$ & - & - & $\checkmark$ & - & - & - & - & - & $\checkmark$ & - & - & - & $\checkmark$ & $\checkmark$ & 6 \\
\hline $\begin{array}{l}\text { Enhancing the degree of } \\
\text { honesty between buyer and } \\
\text { supplier }\end{array}$ & - & $\checkmark$ & $\checkmark$ & - & - & $\checkmark$ & - & - & - & - & - & $\checkmark$ & - & - & - & - & $\checkmark$ & - & 5 \\
\hline $\begin{array}{l}\text { Enhancing the degree of } \\
\text { integrity between buyer and } \\
\text { supplier }\end{array}$ & - & $\checkmark$ & $\checkmark$ & - & - & - & - & - & - & - & - & $\checkmark$ & - & - & - & $\checkmark$ & $\checkmark$ & - & 5 \\
\hline $\begin{array}{l}\text { Contributing to greater } \\
\text { business retention }\end{array}$ & $\checkmark$ & - & - & - & - & - & - & - & $\checkmark$ & - & - & - & - & $\checkmark$ & - & $\checkmark$ & - & - & 4 \\
\hline $\begin{array}{l}\text { Reducing operational } \\
\text { complexity between buyer and } \\
\text { supplier }\end{array}$ & $\checkmark$ & - & - & $\checkmark$ & - & - & - & $\checkmark$ & - & - & - & - & - & - & - & - & $\checkmark$ & - & 4 \\
\hline
\end{tabular}

RIS, risk information sharing. 
Furthermore, the establishment of a personal relationship ensures a long-term relationship among parties, resulting in the regular sharing of SCRI (Li et al. 2015:86). Collaboration among SCPs is enhanced when a personal relationship exists, resulting in the improved and transparent sharing of SCRI, as seen in the quotation:

'Obviously the better the relationship a buyer has got with the supplier in this particular category, the better the chances [are] that ... uh, if something does happen, he will be able to access some stock if the supplier has got limited stock or there are issues relating to the provision of stock.' (P12, male, logistics director)

Participants stated that a personal relationship makes SCPs more comfortable. When people are at ease in a personal relationship, risk information is shared more openly beyond the contractual obligations. The following quotation clearly illustrates this point:

\begin{abstract}
'If you're more comfortable with someone, you [are] obviously going to give them a little bit more, um ... where[-as] if it's strictly professional, you're going to keep your ... your sensitive information to yourself; where[-as] if you trust someone, you're more willing to ... to tell them sensitive information.' (P2, female, transport operations manager)
\end{abstract}

These findings regarding better collaboration and more comfort are in alignment with the findings in current literature. Collaboration, as a result of a personal relationship, can be described as working towards improvement for either SCP (Jin et al. 2013:205). Personal credibility in a personal relationship refers to the level of confidence and comfort between parties (Barnes et al. 2015:38; Wang et al. 2016:843).

Participants mentioned that by establishing a personal relationship with an SCP, both individuals gain a higher level of understanding of each other's operations. The quality of understanding of operations for the SCPs leads to improved RIS. The following quotation clearly illustrates this point:

'Better understanding between the two parties.' (P11, female, non-executive logistics manager)

A personal relationship would ensure that SCPs share similar values, which will support the sharing of risk information. Therefore, the existence of a personal relationship forms the cornerstone of the successful sharing of risk information, as without the personal relationship, partners will not be open to RIS. The following quotations illustrates this point:

'You would probably tend to gravitate to somebody that is like-minded and that has a similar mindset.' (P4, male, regional executive)

'Well, the relationship between the partners is very important. It's something, as far as I'm concerned, [that is] mandatory in this kind of business.' (P18, male, customer service parts and warehousing manager)

The aforementioned findings are in alignment with those in current literature, as personal relationships support communication, allowing individuals to share information with one another and gain a mutual understanding (Barnes et al. 2015:38; Wang et al. 2016:843). Trust among SCPs is increased as a result of shared similar characteristics in a personal relationship (Gligor \& Holcomb 2013:330). The existence of this kind of relationship is based on give and take; as a result, the exchange creates interdependence among the parties involved (Mocke et al. 2016:2).

The findings indicate that a personal relationship enhances the level of honesty and integrity among SCPs; as a result, the partners are more prone to sharing SCRI. These findings expand on current literature and are supported by the following quotations:

'Level of honesty and there is a corresponding level of ... of trust between the two parties that ... that might favour, that you [are] sharing information to certain of your clients versus just the food basket.' (P12, male, logistics director)

'Um, I think definitely honesty, integrity, making sure that you always communicate the right stuff.' (P2, female, transport operations manager)

Participants also mentioned that a personal relationship contributes towards greater business retention and reduced complexity, because SCPs are more inclined to share SCRI with each other. These findings represent an expansion on current literature and are supported by the following quotations:

'There's really only one ... um, that sits right at the top of everything. And that's business retention.' (P14, male, national customs manager)

'Having a good relationship or a good working relationship that allows the business to be a bit more flexible and a little more agile ... so you get things done quicker.' (P8, male, operations manager)

\section{Theme 2: The behavioural attributes required for risk information sharing}

The behavioural attributes required in a personal relationship to share risk information can be seen in Table 3 .

Participants suggested that honesty and trust are the most desired behavioural attributes in a personal relationship before sharing risk information. Participants indicated that without honesty and trust, they would not consider sharing risk information. This can be seen in the following quotations:

'Someone that's honest. Honesty, trusting, trusting is ... is vital.' (P18, male, customer service parts and warehousing manager)

'I think trust is ... definitely has [to] be number one. Um ... you would need to trust each other.' (P10, male, district assistant manager)

Some participants stated that the longevity of the personal relationship is vital to the sharing of risk information, as SCPs are not willing to share risk information with individuals with whom they have not spent an adequate amount of time. This is supported by the following quotation:

'Without a doubt, time spent in your organisation, in that organisation [is] time spent in the industry.' (P9, male, business development executive) 
TABLE 3: Frequency of behavioural attributes required in a personal relationship to share risk information.

\begin{tabular}{|c|c|c|c|c|c|c|c|c|c|c|c|c|c|c|c|c|c|c|c|}
\hline \multirow[t]{2}{*}{ Sub-themes } & \multicolumn{19}{|c|}{ Participants } \\
\hline & 1 & 2 & 3 & 4 & 5 & 6 & 7 & 8 & 9 & 10 & 11 & 12 & 13 & 14 & 15 & 16 & 17 & 18 & Total \\
\hline Honesty & - & $\checkmark$ & $\checkmark$ & $\checkmark$ & $\checkmark$ & $\checkmark$ & $\checkmark$ & $\checkmark$ & - & $\checkmark$ & $\checkmark$ & - & - & - & $\checkmark$ & - & - & $\checkmark$ & 11 \\
\hline Trust & $\checkmark$ & $\checkmark$ & - & $\checkmark$ & - & - & $\checkmark$ & $\checkmark$ & - & $\checkmark$ & $\checkmark$ & - & $\checkmark$ & - & - & $\checkmark$ & $\checkmark$ & $\checkmark$ & 11 \\
\hline Reliability & $\checkmark$ & - & $\checkmark$ & - & $\checkmark$ & - & $\checkmark$ & $\checkmark$ & $\checkmark$ & - & $\checkmark$ & - & $\checkmark$ & $\checkmark$ & - & - & $\checkmark$ & - & 10 \\
\hline Accountability & - & $\checkmark$ & $\checkmark$ & - & - & $\checkmark$ & - & - & $\checkmark$ & $\checkmark$ & $\checkmark$ & - & - & $\checkmark$ & - & $\checkmark$ & $\checkmark$ & - & 9 \\
\hline $\begin{array}{l}\text { Approach- } \\
\text { ability }\end{array}$ & - & $\checkmark$ & $\checkmark$ & - & - & $\checkmark$ & - & - & $\checkmark$ & - & $\checkmark$ & - & $\checkmark$ & - & - & - & - & $\checkmark$ & 7 \\
\hline Humbleness & - & $\checkmark$ & - & $\checkmark$ & - & $\checkmark$ & $\checkmark$ & - & - & - & - & $\checkmark$ & - & - & - & $\checkmark$ & - & $\checkmark$ & 7 \\
\hline $\begin{array}{l}\text { Willingness to go the extra } \\
\text { mile for one another }\end{array}$ & - & $\checkmark$ & $\checkmark$ & - & - & - & $\checkmark$ & - & - & - & $\checkmark$ & - & $\checkmark$ & - & - & $\checkmark$ & - & $\checkmark$ & 7 \\
\hline Consistency & $\checkmark$ & - & - & - & - & - & $\checkmark$ & - & - & $\checkmark$ & $\checkmark$ & - & - & $\checkmark$ & $\checkmark$ & - & - & - & 6 \\
\hline Integrity & - & $\checkmark$ & $\checkmark$ & - & - & $\checkmark$ & - & - & - & $\checkmark$ & - & - & $\checkmark$ & $\checkmark$ & - & - & $\checkmark$ & - & 6 \\
\hline Longevity & $\checkmark$ & - & - & - & - & - & - & $\checkmark$ & $\checkmark$ & - & - & $\checkmark$ & - & - & - & - & - & - & 4 \\
\hline Extroversion & - & $\checkmark$ & - & - & - & - & - & - & - & - & - & - & - & - & - & - & - & $\checkmark$ & 2 \\
\hline
\end{tabular}

TABLE 4: Frequency of challenges associated with risk information sharing.

\begin{tabular}{|c|c|c|c|c|c|c|c|c|c|c|c|c|c|c|c|c|c|c|c|}
\hline \multirow[t]{2}{*}{ Sub-themes } & \multicolumn{19}{|c|}{ Participants } \\
\hline & 1 & 2 & 3 & 4 & 5 & 6 & 7 & 8 & 9 & 10 & 11 & 12 & 13 & 14 & 15 & 16 & 17 & 18 & Total \\
\hline $\begin{array}{l}\text { Not knowing where to draw the } \\
\text { line in RIS }\end{array}$ & - & - & $\checkmark$ & $\checkmark$ & $\checkmark$ & $\checkmark$ & - & $\checkmark$ & $\checkmark$ & $\checkmark$ & $\checkmark$ & - & $\checkmark$ & - & $\checkmark$ & $\checkmark$ & $\checkmark$ & - & 12 \\
\hline $\begin{array}{l}\text { Making oneself and the } \\
\text { company vulnerable }\end{array}$ & - & - & $\checkmark$ & $\checkmark$ & $\checkmark$ & $\checkmark$ & - & $\checkmark$ & $\checkmark$ & $\checkmark$ & $\checkmark$ & $\checkmark$ & $\checkmark$ & - & $\checkmark$ & - & $\checkmark$ & - & 12 \\
\hline $\begin{array}{l}\text { Management of confidential } \\
\text { information }\end{array}$ & - & - & - & $\checkmark$ & $\checkmark$ & - & - & $\checkmark$ & $\checkmark$ & - & $\checkmark$ & - & - & $\checkmark$ & $\checkmark$ & $\checkmark$ & - & $\checkmark$ & 9 \\
\hline $\begin{array}{l}\text { Damaging the relationship with } \\
\text { the company }\end{array}$ & - & - & $\checkmark$ & $\checkmark$ & - & $\checkmark$ & - & - & $\checkmark$ & $\checkmark$ & - & $\checkmark$ & - & $\checkmark$ & - & $\checkmark$ & - & - & 8 \\
\hline $\begin{array}{l}\text { Not knowing where the } \\
\text { personal relationship ends }\end{array}$ & - & $\checkmark$ & - & - & - & $\checkmark$ & - & $\checkmark$ & - & $\checkmark$ & $\checkmark$ & - & - & - & $\checkmark$ & - & $\checkmark$ & $\checkmark$ & 8 \\
\hline $\begin{array}{l}\text { Going to rivals with confidential } \\
\text { information }\end{array}$ & - & - & $\checkmark$ & $\checkmark$ & $\checkmark$ & - & - & - & $\checkmark$ & - & - & $\checkmark$ & - & - & - & $\checkmark$ & $\checkmark$ & - & 6 \\
\hline $\begin{array}{l}\text { Developing a sense of obligation } \\
\text { towards that individual, due to } \\
\text { the personal relationship }\end{array}$ & - & - & - & - & $\checkmark$ & $\checkmark$ & - & - & - & $\checkmark$ & - & - & - & $\checkmark$ & - & - & - & $\checkmark$ & 5 \\
\hline
\end{tabular}

The aforementioned findings are in alignment with existing literature, as logistics managers are more willing to share risk information when they can be honest with their SCPs (Gligor \& Esmark 2015:519). Trust is important due to its sensitive role in RIS (Vermeulen et al. 2016:6). An influential factor in a personal relationship is the length of the relationship, due to the benefits of sharing knowledge (Vaidya \& Hudnurkar 2013:293).

In this study, behavioural attributes identified, not evident in the literature, include accountability, reliability, approachability, humbleness, willingness to go the extra mile for one another, consistency, integrity and extroversion. Supply chain partners need to be approachable as a personal relationship is a two-way street and the sharing of risk information requires SCPs to be able to communicate in all simplicity and assurance with one another. Supply chain partners have no need being arrogant; rather one should be humble and empathetic to others in their circumstances, as today you might be the one sharing risk information; however, tomorrow you might be in need of such risk information. The willingness to go the extra mile for one another is vital in any personal relationship. Consistency among SCPs is important as it refers to being stable and dependable, both attributes required in order to effectively share SCRI. Integrity refers to SCPs being true to their word, whether it is sharing risk information or keeping shared information confidential. Finally, a SCP must be extroverted and easy to communicate with, otherwise the sharing of risk information will be a difficult and formal process. These findings are supported by the following quotations, which are presented in the same sequence as discussed:

'Someone whom you would be accountable to for the actions.' (P16, male, senior outbound manager)

'Reliability, consistency. Um ... we are in it together and [do] teamwork.' (P7, female, head of supply chain and strategic sourcing)

'He's very approachable.' (P3, male, transport operations manager)

'Because of our relationship ... I do ... I do go the extra mile and ... and likewise, they on that side of the fence, they tell me stuff and they ... whenever there's red, then they'll flag it to me.' (P3, male, transport operations manager)

'Integrity. So true to your word.' (P8, male, operations manager)

'It helps to be an extrovert. If you're an introvert, you don't like people. I have found that they do struggle.' (P2, female, transport operations manager)

\section{Theme 3: The challenges associated with risk information sharing}

The challenges associated with RIS when a personal relationship exists are presented in Table 4.

Participants stated that the main challenge, associated with RIS, is when SCPs do not know where to draw the line 
regarding the sharing of risk information, resulting in SCPs sharing risk information with their SCP that they are not supposed to or are not authorised to share. This finding is an addition to literature and can be seen in the following quotation:

'If you don't know where to draw the line, yeah, then ... then you're going to open yourself $[u p]$ to those challenges.' (P3, male, transport operations manager)

The study found that the possibility of making oneself vulnerable when sharing risk information is a challenge to participants. Furthermore, managing the sharing of risk information is also a major challenge, because once the risk information is shared, preventing that information from being shared again by the SCP is extremely difficult, if not impossible. This is apparent in the following quotations:

'You could say things that you really shouldn't have said and then the other guy, you know, have a conversation in the corridor in their company and shares it with somebody else in confidence and then that person goes and tell somebody, and then, you know, it ultimately could open you up to risk and liability issues.' (P13, male, director of operations and solutions)

'There are huge problems that come with that because, for example, if our manufacturing [division] shared information about the ingredients; again, it's going to be a problem in it [sic] because then somebody else is going to have seen it.' (P5, male, national logistics manager)

These findings are supported by literature. The vulnerability caused by RIS increases parallel to an increase in supply chain complexities (Bode \& Wagner 2015:216; Habermann et al. 2015:493). Convincing SCPs to share risk information is a major challenge in itself, directly linked to the management and decisions regarding the risk information (Li et al. 2015:84).

Participants identified two challenges, which are not included in existing literature, namely damaging the personal relationship with either the 3PL or client firm, due to RIS, because once risk information is shared with a SCP, it creates an expectation. Should risk information then again not be shared, it could create conflict and in the end damage the personal relationship. In addition, when SCPs do not know where the personal relationship ends in terms of RIS, it also becomes a challenge. Supply chain partners who develop too close a personal relationship expose themselves to the challenge of sharing risk information beyond the recommended and authorised boundaries. These challenges are illustrated in the following quotations:

'The challenge is the degradation of the relationship. Um ... and then also the loss of the business, loss of the partnership.' (P14, male, national customs manager)

'If the relationship becomes very close, you've always got to be careful of not talking beyond certain boundaries.' (P15, male, contract logistics manager)

Finally, the last two notable challenges indicated by some of the participants were the development of a sense of obligation towards the SCP when sharing risk information due to the personal relationship. The personal relationship makes one feel obliged to share risk information with the SCP; thus, the information is shared, not based on the value of the information, but rather on that of the personal relationship. Furthermore, SCPs could use the shared risk information against you by going to rivals with the confidential information. These challenges expand on current literature regarding the challenges associated with personal relationships and RIS. The following quotations touch on these challenges:

'I mean, you kind of feel obligated to the person that you're dealing with that you're friends with.' (P5, male, national logistics manager)

'Inevitably you ... you work in an environment where you can share information that a supplier might use with some of his other clients.' (P10, male, district assistant manager)

\section{Theme 4: The security risks associated with risk information sharing}

The security risks associated with RIS, when a personal relationship exists, are presented in Table 5.

Participants identified the leakage of private information and the loss of intellectual property as the main security risks associated with personal relationships in RIS. The loss of intellectual property is directly linked to risk information sharing, as in a personal relationship SCPs may acquire access to intellectual property:

'Relationship leads to those security risks of leakage of information or the abuse of personal information.' (P5, male, national logistics manager)

TABLE 5: Frequency of security risks associated with risk information sharing.

\begin{tabular}{|c|c|c|c|c|c|c|c|c|c|c|c|c|c|c|c|c|c|c|c|}
\hline \multirow[t]{2}{*}{ Sub-themes } & \multicolumn{19}{|c|}{ Participants } \\
\hline & 1 & 2 & 3 & 4 & 5 & 6 & 7 & 8 & 9 & 10 & 11 & 12 & 13 & 14 & 15 & 16 & 17 & 18 & Total \\
\hline Leakage of private information & - & - & - & $\checkmark$ & $\checkmark$ & $\checkmark$ & - & $\checkmark$ & $\checkmark$ & $\checkmark$ & $\checkmark$ & $\checkmark$ & $\checkmark$ & - & $\checkmark$ & $\checkmark$ & - & $\checkmark$ & 12 \\
\hline The loss of intellectual property & - & - & $\checkmark$ & $\checkmark$ & - & $\checkmark$ & - & $\checkmark$ & $\checkmark$ & $\checkmark$ & $\checkmark$ & $\checkmark$ & $\checkmark$ & - & $\checkmark$ & $\checkmark$ & - & $\checkmark$ & 12 \\
\hline $\begin{array}{l}\text { Unintentional disclosure of } \\
\text { confidential information }\end{array}$ & - & - & $\checkmark$ & $\checkmark$ & - & $\checkmark$ & - & $\checkmark$ & $\checkmark$ & $\checkmark$ & $\checkmark$ & $\checkmark$ & $\checkmark$ & - & $\checkmark$ & - & - & $\checkmark$ & 11 \\
\hline $\begin{array}{l}\text { Intentional abuse of confidential } \\
\text { information }\end{array}$ & $\checkmark$ & - & - & $\checkmark$ & $\checkmark$ & - & - & - & $\checkmark$ & - & - & $\checkmark$ & $\checkmark$ & - & $\checkmark$ & $\checkmark$ & - & - & 8 \\
\hline Supplier becoming a competitor & - & - & $\checkmark$ & $\checkmark$ & - & $\checkmark$ & - & - & - & - & $\checkmark$ & $\checkmark$ & - & $\checkmark$ & $\checkmark$ & $\checkmark$ & - & - & 8 \\
\hline $\begin{array}{l}\text { Not willing to sign the company's } \\
\text { NDA }\end{array}$ & $\checkmark$ & - & - & - & - & - & - & - & - & - & - & - & - & - & - & - & - & - & 1 \\
\hline
\end{tabular}

NDA, Non-disclosure Agreement. 
'It gives them access to how we run and control managers, how we run our risk and security? Where do we store our firearms? You know, all of that information in the wrong hands can lead to a problem and ... expose our weaknesses and include exposing things to clients that we don't want to expose or to competitors.' (P4, male, regional executive)

The aforementioned findings are in alignment with literature. The main security risk associated with RIS is information leakages (Colicchia et al. 2018:14). The loss of intellectual property is seen as the ultimate risk when sharing SCRI (Huong Tran et al. 2016:1119).

Furthermore, participants mentioned that SCPs are faced with the challenge of unintentionally disclosing confidential information. This is evident in the following quote:

'You've built this relationship, um ... things are going well and stuff, and sometimes I think information is shared that shouldn't be shared. Um, [it] just [depends] on how comfortable you are with each other.' (P11, female, non-executive logistics manager)

Some participants mentioned the intentional abuse and disclosure of confidential information as a security risk. Supply chain partners gain access to risk and confidential information through the established personal relationship and then abuse that relationship by disclosing confidential information to other SCPs and even possible competitors. This is evident in the following quote:

'Like going directly tell customers that's the risk on its own [is] a very big one.' (P1, female, inbound logistics manager)

These findings confirm existing literature regarding security risks associated with personal relationships and RIS. The unintentional or intentional disclosure of confidential information to unauthorised parties is seen as a security risk of RIS (Tan et al. 2016:622). Direct disclosure is the act of disclosing sensitive information, mistakenly identified as non-confidential information, and therefore shared with SCPs (Zhang et al. 2012:1355).

Finally, the last two notable security risks indicated during the study expand on current literature regarding the security risk associated with personal relationships in RIS. Firstly, when a supplier becomes a competitor as a result of the sharing of risk information in a relationship. Risk information sharing comes to a point where the SCP has gained an adequate amount of risk information and uses it against one in order to serve the same market. Secondly, when SCPs are not willing to sign the company's NDA, it is seen as a security risk, because the SCP will then have the right to share any and all information available to them as there are no legal requirements preventing them from doing so. These quotations illustrate the security risks mentioned:

'So I think it goes back to, am I able to talk to you confidentially and are you ... am I certain you're not going to use that information for your own gain?' (P4, male, regional executive)

'But obviously we have risk where some suppliers do not want to sign our agreement.' (P1, female, inbound logistics manager)

\section{Theme 5: Information sharing risk mitigation}

The strategies identified to mitigate information sharing risk are presented in Table 6 .

Both buyers and suppliers predominantly use the legal aspect of the matter to mitigate the sharing of risk information among SCPs. Participants indicated that to mitigate the risk, they highly depend on the implementation of the code of conduct and the code of ethics to govern the sharing of risk information among SCPs. In addition, eight participants indicated that their firms implement a standard NDA to be signed by both parties as their strategy towards mitigating the sharing of risk information. See the following quotes:

'So we do a bit of work around employee engagement; [it] was [in] that code of conduct and how that impacts in his toolbox talks.' (P4, male, regional executive)

'So we do have $[a]$ code of ethics that ... that talk quite strictly to [sic], uh ... relationships with suppliers. And how those are managed.' (P4, male, regional executive)

'So I think the NDA is a big part of that.' (P7, female, head of supply chain and strategic sourcing)

These findings are in alignment with existing literature regarding information sharing risk mitigation. Compliance with the code of conduct increases the effective sharing of information and reduces the risks associated with it (Delbufalo \& Bastl 2018:1248). Enforcing the code of ethics bestows a sense of ethical and honest behaviour and, in doing so, it reduces the risk of information sharing (Banks 2010:341). To promote transparency regarding the sharing of risk information, an NDA may be implemented to govern the sharing of all information (Horák et al. 2019:6).

TABLE 6: Frequency of codes for information sharing risk mitigation.

\begin{tabular}{|c|c|c|c|c|c|c|c|c|c|c|c|c|c|c|c|c|c|c|c|}
\hline \multirow[t]{2}{*}{ Sub-themes } & \multicolumn{19}{|c|}{ Participants } \\
\hline & 1 & 2 & 3 & 4 & 5 & 6 & 7 & 8 & 9 & 10 & 11 & 12 & 13 & 14 & 15 & 16 & 17 & 18 & Total \\
\hline Code of ethics & - & - & - & $\checkmark$ & - & $\checkmark$ & - & $\checkmark$ & $\checkmark$ & $\checkmark$ & $\checkmark$ & $\checkmark$ & $\checkmark$ & - & $\checkmark$ & - & $\checkmark$ & $\checkmark$ & 11 \\
\hline Code of conduct & - & - & - & $\checkmark$ & - & $\checkmark$ & - & $\checkmark$ & $\checkmark$ & $\checkmark$ & $\checkmark$ & $\checkmark$ & - & - & $\checkmark$ & - & $\checkmark$ & $\checkmark$ & 10 \\
\hline Making use of an NDA & $\checkmark$ & - & $\checkmark$ & - & - & $\checkmark$ & $\checkmark$ & $\checkmark$ & - & - & - & - & - & $\checkmark$ & - & $\checkmark$ & $\checkmark$ & - & 8 \\
\hline Proactive collaboration & - & $\checkmark$ & - & $\checkmark$ & - & - & - & - & $\checkmark$ & - & - & - & - & - & $\checkmark$ & $\checkmark$ & $\checkmark$ & $\checkmark$ & 7 \\
\hline Making use of SLAs & - & - & - & - & - & - & $\checkmark$ & - & - & - & $\checkmark$ & $\checkmark$ & $\checkmark$ & - & - & $\checkmark$ & - & $\checkmark$ & 6 \\
\hline Making use of KPIs & - & - & - & - & - & - & - & - & - & - & $\checkmark$ & $\checkmark$ & $\checkmark$ & - & - & - & - & - & 3 \\
\hline Removing the individual & - & - & - & - & $\checkmark$ & $\checkmark$ & - & - & - & - & - & - & - & - & - & - & - & - & 2 \\
\hline Integrity due diligence & - & - & - & - & - & - & - & - & - & - & - & - & - & $\checkmark$ & - & - & - & - & 1 \\
\hline
\end{tabular}

NDA, non-disclosure agreement; SLA, Service level agreement KPI, Key performance indicator. 
The study found that some participants make use of two strategies, namely collaborative planning, forecasting and replenishment (CPFR), as well as SLAs. By making use of CPFR, the firm is able to manage the information sharing risk by mitigating in advance the possibility thereof and by being proactive in its operations. The use of SLAs ensures that SCPs have to uphold a certain level of service and professionalism; it also ensures that risks regarding information sharing are addressed and mitigated in advance. As seen in the following quotations:

'I think it does help us mitigate risk because we can be more proactive.' (P2, female, transport operations manager)

'We've just got service level agreements.' (P11, female, nonexecutive logistics manager)

These findings are in alignment with existing literature regarding strategies for mitigating RIS as mentioned in literature, namely management of information flows and monitoring the relationships and risks (Lavastre et al. 2014:3396).

The study found that a small number of participants make use of KPIs and the direct dismissal of individuals to mitigate the risk of sharing risk information when a personal relationship is present. These findings expand on current literature regarding the mitigation strategies of RIS in a personal relationship. These quotations illustrate these strategies:

'We've got KPIs and service level agreements.' (P12, male, logistics director)

'At some stage you need to trust people. Um ... and that's the other thing. If somebody ... if you give everybody trust and the first person that lets you down, then you've got to cut them out and cut them out [so] hard that unfortunately everybody else realises.' (P6, male, managing director)

Finally, a single participant indicated that their firm makes use of integrity due diligence (IDD) in order to mitigate the information sharing risk in a personal relationship. This finding expands on current literature regarding the mitigation strategies of RIS in a personal relationship. The following quotation supports the finding:

'What we do, is what we call an IDD. It's an integrity due diligence.' (P14, male, national customs manager)

\section{Conclusion}

\section{Discussion of the findings}

The purpose of this study was to investigate the role of personal relationships in supply chain RIS from the perspective of buyers and suppliers in the South African 3PL context. In this study findings in five areas are reported in an attempt to answer the corresponding five research questions. These areas relate to the following: (1) the role of personal relationships in RIS; (2) the behavioural attributes required for RIS; (3) the challenges associated with RIS; (4) the security risks associated with RIS; (5) information sharing risk mitigation. The first research question explored the role personal relationships play in RIS between the buyers and suppliers of logistics services. In the study it is found that personal relationships build trust, and strong trust results in increased RIS among SCPs. It was also found that due to the existence of a personal relationship with an $\mathrm{SCP}$, the willingness to share risk information is enhanced, due to mutual interest. Furthermore, the findings show that in order for RIS to take place, a long-term personal relationship is important, otherwise SCPs will not feel secure enough to share risk information. The study's findings confirm those of $\mathrm{Li}$ et al. (2015:86) who claimed that in order for SCRI to be shared, a long-term relationship must first be established. The findings also indicate that the existence of a personal relationship among SCPs encourages collaboration, leading to improved RIS due to the establishment of frequent communication channels. The results of the study confirm that collaboration is a result of a personal relationship and teamwork. However, additional roles of personal relationships, not evident in literature, were identified, such as increasing the degree of openness among SCPs and raising the level of honesty and integrity among SCPs, due to the existence of a personal relationship, resulting in improved RIS. Finally, personal relationships contribute positively towards greater business retention and reduce overall complexity, because of the increase in supply chain visibility gained by the effective sharing of risk information among SCPs.

The second research question discloses what personal behavioural attributes are required to ensure the sharing of SCRI between buyers and suppliers. The findings indicate that trust and honesty are the main behavioural attributes SCPs look for when establishing a personal relationship in order to share risk information. The findings demonstrate that the longevity of a personal relationship plays a vital role in SCPs being willing and open towards RIS, as longevity indicates a sense of commitment. In addition to existing literature, a vast range of behavioural attributes required within a personal relationship in order to share risk information were found such as: accountability, reliability, approachability, humbleness, willingness to go the extra mile for one another, consistency, integrity and a degree of extroversion. The most significant being the accountability and reliability of the SCP. These attributes expanded on existing literature.

The third research question examined what challenges are associated with SCRI sharing when a personal relationship exists between a buyer and supplier of logistics services. Sharing risk information in a personal relationship opens the possibility of making oneself vulnerable. These findings confirm the current literature regarding the increase in vulnerability, due to RIS and the complexity thereof.

The existence of a personal relationship increases the complexity of managing RIS, as risk information is shared more freely in a personal relationship; however, that information may also be shared easily in the following personal relationship outside the firm. The findings indicate 
that a major challenge in a personal relationship and RIS is when SCPs do not know where to draw the line with regard to RIS, which may result in SCPs sharing risk information they are not supposed to. The study further found that a challenge associated with RIS in a personal relationship is when SCPs do not respect the boundaries of the relationship and the SCPs may use the RIS against you by sharing the RIS with rivals.

The fourth research question assessed the security risks associated with supply chain RIS when a personal relationship exists between a buyer and supplier of logistics services. The main security risks are the leakage of private information and the loss of possible intellectual property. The existing literature on security risks associated with RIS was corroborated during the study. The results show that the unintentional disclosure of confidential information and the intentional abuse and disclosure of confidential information are further challenges linked to RIS in a personal relationship. However, in addition, the study's findings expand on current literature by identifying that SCPs becoming competitors and SCPs not willing to sign the NDA are challenges directly linked to personal relationships and RIS, because an SCP may gain access to the risk information due to the existence of a personal relationship and the risk information being shared.

The fifth research question determined how information sharing risk is mitigated when a personal relationship exists between a buyer and a supplier of logistics services. Most firms have a code of conduct, a code of ethics and a standard NDA in order to mitigate the sharing of risk information. The three methods are used because they govern the decisionmaking process of each employee regarding RIS, especially when working with a client with whom a personal relationship has been established, confirming existing literature on the mitigation of information sharing risk.

The findings indicate that firms make use of CPFR and SLAs when a personal relationship is present and risk information is being shared among SCPs in an attempt to ensure effective information sharing risk mitigation. Both CPFR and SLAs empower the employer to proactively try and manage any possible future risks associated with RIS, as both methods are implemented in advance in order to guide staff in the personal relationships they establish. In addition to existing literature, it was found that to mitigate risk, firms make use of either KPIs or the direct dismissal of an offending individual. It was also found that for information sharing risk to be mitigated, firms make use of IDD when a personal relationship exists among SCPs.

\section{Managerial implications and recommendations}

Firms need to identify a viable approach to managing personal relationships with SCPs. The reason for this is because the existence of personal relationships with SCPs is frequent and the RIS goes hand in hand with it. Personal relationships with SCPs predominantly build trust and enhance openness, collaboration and the willingness to share; for this reason, management should rather focus on proactively managing the personal relationships in order to gain a competitive advantage. By promoting the development of personal relationships with SCPs, a better quality of risk information will be shared by both parties leading to enhanced performance and business retention. However, managers must ensure that a clear distinction is made between an appropriate personal relationship and a personal relationship that is too close and, therefore, represents a risk to the firm. Managers must find a way to ensure that when a personal relationship is established with an SCP, the required behavioural attributes are present. This is especially important when risk information is to be shared. When firms identify a possible personal relationship between an employee and their SCP, they should consider reminding the employee of the desired behavioural attributes the firm looks for.

Thirdly, the findings identify possible challenges to sharing risk information when a personal relationship is present. Managers need to ensure that even though such relationships with SCPs are beneficial, the relationship should not increase the complexity of managing confidential information, as this may counteract the benefits gained. Managers must make sure that adequate measures are put into place to ensure that both parties clearly understand the difference between a business relationship and a personal relationship with an SCP. This can be done by implementing a process of frequent communication with staff members regarding the importance of discerning between the two at all times. Management must have greater control over the sharing of RIS among SCPs and be able to rely on the accountability of staff members. This can be ensured by having employees sign an agreement stating that they will not share confidential information with parties outside the firm. Furthermore, if one chooses to share confidential information, one would be held accountable for possible losses or damages as a result of the shared information.

Managers should stay up to date with current strategies in order to mitigate information sharing risk due to a personal relationship among SCPs. Current methods of mitigation, such as the use of codes of conduct, codes of ethics and NDAs, are well established; however, SCPs are still willing to share risk information in a personal relationship. Management needs to identify new ways of keeping employees accountable for their actions, especially when sharing risk information with SCPs in a personal relationship. This can be done by frequently reminding staff members that they are dealing with confidential and sensitive information and for that reason should not share it beyond what is expected of them.

\section{Limitations and directions for future research}

This study utilised a qualitative research design with a relatively small sample to explore the role of personal relationships in supply chain RIS. Researchers may consider using other research designs and data collection methods such as survey research or mixed methods to assess the influence, 
the strength and the nature of personal relationships on the level of supply chain RIS. Furthermore, the study focused on the dyadic perspectives of the relationship between 3PLs and clients. Future studies may make use of a triadic approach by including first, second and third parties in the personal relationship. The study focused specifically on the 3PL industry in South Africa; therefore, research can be conducted in other industries and settings in a developed country with different laws, regulations, and community pressures.

\section{Acknowledgements Competing interests}

The authors declare that they have no financial or personal relationships that may have inappropriately influenced them in writing this article.

\section{Author's contributions}

This article is based on the M.Phil. dissertation of M.v.d.W. who was the main researcher. W.N. and A.M. acted as supervisors determining the conceptualisation, literature review, the research instrument and development of this manuscript.

\section{Funding information}

This research received no specific grant from any funding agency in the public, commercial or not-for-profit sectors.

\section{Data availability}

Data are stored according to institutional policy.

\section{Disclaimer}

The views and opinions expressed in this article are those of the authors and do not necessarily reflect the official policy or position of any affiliated agency of the authors.

\section{References}

Ab Talib, M.S., Abdul Hamid, A.B. \& Thoo, A.C., 2015, 'Critical success factors of supply chain management: A literature survey and Pareto analysis', EuroMed Journal of Business 10(2), 234-263. https://doi.org/10.1108/EMJB-09-2014-0028

Ali, I.L., Hird, A. \& Whitfield, R.I., 2018, 'Social relationships and supply chain risk information sharing', paper presented at the 25th International Annual EurOMA Conference, Budapest, Hungary, June 24-27, 2018, pp. 1-10.

Allan, G., 1989, Friendship, Westview Press, Boulder, CO.

Ambulkar, S., Blackhurst, J. \& Grawe, S., 2015, 'Firm's resilience to supply chain disruptions: Scale development and empirical examination' Journal of Operation Management 33(1), 111-122. https://doi.org/10.1016/j.jom.2014.11.002

Asif Salam, M., 2011, 'Supply chain commitment and business process integration: The implications of Confucian dynamism', European Journal of Marketing 45(3) 358-382. https://doi.org/10.1108/03090561111107230

Banks, S., 2010, 'Interprofessional ethics: A developing field?', Ethics and Social Welfare 4(3), 280-294. https://doi.org/10.1080/17496535.2010.516116

Barnes, B.R., Leonidou, L.C., Siu, N.Y. \& Leonidou, C.N., 2015, 'Interpersonal factors as drivers of quality and performance in Western-Hong Kong interorganizational business relationships', Journal of International Marketing 23(1), 23-49. https:// doi.org/10.1509/jim.14.0008

Bode, C. \& Wagner, S.M., 2015, 'Structural drivers of upstream supply chain complexity and the frequency of supply chain disruptions', Journal of Operations Management 36(1), 215-228. https://doi.org/10.1016/j.jom.2014.12.004

Brandon-Jones, E., Squire, B., Autry, C.W. \& Petersen, K.J., 2014, 'A contingent resource-based perspective of supply chain resilience and robustness', Journal of Supply Chain Management 50(3), 55-73. https://doi.org/10.1111/jscm.12050
Cachia, M. \& Millward, L., 2011, 'The telephone medium and semi-structured interviews: A complementary fit', Qualitative Research in Organizations and Management: An International Journal 6(3), 265-277. https://doi.org/10.1108/17465641111188420

Colicchia, C., Creazza, A., Noè, C. \& Strozzi, F., 2018, 'Information sharing in supply chains: A review of risks and opportunities using the systematic literature network analysis (SLNA)', Supply Chain Management: An International Journal 24(1), 5-21. https://doi.org/10.1108/SCM-01-2018-0003

Cooper, D.R. \& Schindler, P.S., 2014, Business research methods,12th edn., McGrawHill, New York, NY.

Creswell, J.W., 2012, Educational research: Planning, conducting and evaluating quantitative and qualitative research, 4th edn., Pearson, Boston, MA.

Creswell, J.W. \& Plano Clark, V.L., 2015, Understanding research: A consumer's guide, 2nd edn., Pearson Education, Upper Saddle River, NJ.

Delbufalo, E. \& Bastl, M., 2018, 'Multi-principal collaboration and supplier's compliance with codes-of-conduct', The International Journal of Logistics Management 29(4), 1237-1254. https://doi.org/10.1108/IJLM-09-2017-0222

Du, T.C., Lai, V.S., Cheung, W. \& Cui, X., 2012, 'Willingness to share information in a supply chain: A partnership-data-process perspective', Information \& Management 49(2), 89-98. https://doi.org/10.1016/j.im.2011.10.003

Durach, C.F. \& Machuca, J.A., 2018, 'A matter of perspective - The role of interpersonal relationships in supply chain risk management', International Journal of Operations \& Production Management 38(10), 1866-1887. https://doi. Operations \& Production Man
org/10.1108/IJOPM-03-2017-0157

Eckerd, S. \& Sweeney, K., 2018, 'The role of dependence and information sharing on governance decisions regarding conflict', The International Journal of Logistics Management 29(1), 409-434. https://doi.org/10.1108/IJLM-12-2016-0301

Elo, S., Kääriäinen, M., Kanste, O., Pölkki, T., Utriainen, K. \& Kyngäs, H., 2014, 'Qualitative content analysis: A focus on trustworthiness', SAGE Open 4(1), 1-10. https://doi.org/10.1177/2158244014522633

Fan, H., Li, G., Sun, H. \& Cheng, T., 2017, 'An information processing perspective on supply chain risk management: Antecedents, mechanism, and consequences', International Journal of Production Economics 185, 63-75. https://doi. org/10.1016/j.ijpe.2016.11.015

Fournier, S., Dobscha, S. \& Mick, D., 1998, 'Preventing the premature death of relationship marketing', Harvard Business Review 76(1), 42-51.

Gligor, D. \& Holcomb, M., 2013, 'The role of personal relationships in supply chains: An exploration of buyers and suppliers of logistics services', The International Journal of Logistics Management 24(3), 328-355. https://doi.org/10.1108/IJLM07-2012-0067

Gligor, D.M. \& Autry, C.W., 2012, 'The role of personal relationships in facilitating supply chain communications: A qualitative study', Journal of Supply Chain Management 48(1), 24-43. https://doi.org/10.1111/j.1745-493X.2011.03240.x

Gligor, D.M. \& Esmark, C.L., 2015, 'Supply chain friends: The good, the bad, and the ugly', Business Horizons 58(5), 517-525.

Grayson, K., 2007, Friendship versus business in marketing relationships, Journal of Marketing 71(4), 121-139. https://doi.org/10.1509/jmkg.71.4.121

Guest, G., Bunce, A. \& Johnson, L., 2006, 'How many interviews are enough? An experiment with data saturation and variability', Field Methods 18(1), 59-82. https://doi.org/10.1177/1525822X05279903

Habermann, M., Blackhurst, J. \& Metcalf, A.Y., 2015, 'Keep your friends close? Supply chain design and disruption risk', Decision Sciences 46(3), 491-526. https://doi. org $/ 10.1111 /$ deci.12138

Havenga, J.H., Simpson, Z.P., King, D. \& De Bod, A.B., M., 2016, Logistics barometer South Africa 2016, University of Stellenbosch, Stellenbosch, viewed 10 March 2019, from https://www.sun.ac.za/english/faculty/economy/logistics/Documents/ Logistics\%20Barometer/Logistics\%20Barometer\%202016\%20Report.pdf.

Horák, M., Stupka, V. \& Husák, M., 2019, 'GDPR compliance in cybersecurity software: A case study of DPIA in information sharing platform', in Proceedings of the 14th International Conference on Availability, Reliability and Security, Kent, August 26-29, 2019, pp. 1-8.

Huong Tran, T.T., Childerhouse, P. \& Deakins, E., 2016, 'Supply chain information sharing Challenges and risk mitigation strategies', Journal of Manufacturing Technology Management 27(8), 1102-1126. https://doi.org/10.1108/JMTM-03-2016-0033

Jie, F., Parton, K.A. \& Cox, R.J., 2013, 'Linking supply chain practices to competitive advantage: An example from Australian agribusiness', British Food Journal 115(7) 1003-1024. https://doi.org/10.1108/BFJ-10-2010-0181

Jin, Y., Fawcett, A.M. \& Fawcett, S.E., 2013, 'Awareness is not enough: Commitment and performance implications of supply chain integration', International Journal of Physical Distribution \& Logistics Management 43(3), 205-230. https://doi. org/10.1108/IJPDLM-10-2011-0169

Jüttner, U. \& Maklan, S., 2011, 'Supply chain resilience in the global financial crisis: An empirical study', Supply Chain Management: An International Journal 16(4), 246259. https://doi.org/10.1108/13598541111139062

Kache, F. \& Seuring, S., 2017, 'Challenges and opportunities of digital information at the intersection of big data analytics and supply chain management', International Journal of Operations \& Production Management 37(1), 10-36. https://doi. org/10.1108/IJOPM-02-2015-0078

Karrapan, C., Sishange, M., Swanepoel, E. \& Kilbourn, P.J., 2017, 'Benchmarking criteria for evaluating third-party logistics providers in South Africa', Journal of Transport and Supply Chain Management 11(1), 1-10. https://doi.org/10.4102/jtscm.v11i0.305

Khan, M., Hussain, M. \& Saber, H.M., 2016, 'Information sharing in a sustainable supply chain', International Journal of Production Economics 181, 208-214. https://doi.org/10.1016/j.ijpe.2016.04.010 
Kim, M. \& Chai, S., 2017, 'The impact of supplier innovativeness, information sharing and strategic sourcing on improving supply chain agility: Global supply chain perspective', International Journal of Production Economics 187, 42-52. https:// doi.org/10.1016/j.ijpe.2017.02.007

Kurniawan, R., Zailani, S.H., Iranmanesh, M. \& Rajagopal, P., 2017, 'The effects of vulnerability mitigation strategies on supply chain effectiveness: Risk culture as moderator', Supply Chain Management: An International Journal 22(1), 1-15. moderator', Supply Chain Management: An
https://doi.org/10.1108/SCM-12-2015-0482

Langley, J. \& Long, M., 2012, Third-party logistics study: The state of logistics outsourcing, viewed 08 March 2019, from https://www.slideshare.net/ DennisWereldsma/3-pl-2012-study.

Lavastre, O., Gunasekaran, A. \& Spalanzani, A., 2014, 'Effect of firm characteristics, supplier relationships and techniques used on supply chain risk management (SCRM): An empirical investigation on French industrial firms', International Journal of Production Research 52(11), 3381-3403. https://doi.org/10.1080/0020 Journal of Production
7543.2013.878057

Leuschner, R., Carter, C.R., Goldsby, T.J. \& Rogers, Z.S., 2014, 'Third-party logistics: A meta-analytic review and investigation of its impact on performance', Journal of Supply Chain Management 50(1), 21-43. https://doi.org/10.1111/jscm.12046

Li, G., Fan, H., Lee, P.K. \& Cheng, T., 2015, 'Joint supply chain risk management: An agency and collaboration perspective', International Journal of Production Economics 164, 83-94. https://doi.org/10.1016/j.ijpe.2015.02.021

Liao, W., Yuan, Y.C. \& McComas, K.A., 2018, 'Communal risk information sharing: Motivations behind voluntary information sharing for reducing interdependent risks in a community', Communication Research 45(6), 909-933. https://doi. risks in a community', Communicat
org/10.1177/0093650215626981

Lietz, C.A. \& Zayas, L.E., 2010, 'Evaluating qualitative research for social work practitioners', Advances in Social Work 11(2), 188-202. https://doi. org/10.18060/589

Liu, C.L. \& Lee, M.Y., 2018, 'Integration, supply chain resilience, and service performance in third-party logistics providers', The International Journal of Logistics Management 29(1), 5-21. https://doi.org/10.1108/IJLM-11-2016-0283

Madenas, N., Tiwari, A., Turner, C. \& Peachey, S., 2015, 'An analysis of supply chain issues relating to information flow during the automotive product development', Journal of Manufacturing Technology Management 26(8), 1158-1176. https:// doi.org/10.1108/JMTM-02-2014-0008

Meyer, A., Niemann, W. \& Kotzé, T., 2017, 'Exploring the dark side of interpersonal relationships between buyers and suppliers of logistics services', Acta Commercii 17(1), 1-12. https://doi.org/10.4102/ac.v17i1.437

Mocke, K., Niemann, W. \& Kotzé, T., 2016, 'The role of personal relationships between buyers and suppliers of third-party logistics services: A South African perspective' Acta Commercii 16(1), 1-13. https://doi.org/10.4102/ac.v16i1.367

Myers, M.D., 2013, Qualitative research in business and management, 2 nd edn., Sage Croydon.

Nahapiet, J. \& Ghoshal, S., 1998, 'Social capital, intellectual capital, and the organizational advantage', Academy of Management Review 23(2), 242-266. https://doi.org/10.5465/amr.1998.533225

Nel, J., De Goede, E. \& Niemann, W., 2018, 'Supply chain disruptions: Insights from South African third-party logistics service providers and clients', Journal of Transport and Supply Chain Management 12(1), 1-12. https://doi.org/10.4102/ jtscm.v12i0.377

Oakes, K., 2012, 'Identifying roadblocks to productivity adds value to the business', Training Industry Quarterly Winter 2012, 40-41, viewed 27 May 2021, from Training Industry Quarterly Winter 2012, 40-41, viewed 27 May 2021, from
https://www.nxtbook.com/nxtbooks/trainingindustry/tiq_2012winter/index. https://www.nxtbook.
php?startid=40\#/p/40.

Percy, W.H., Kostere, K. \& Kostere, S., 2015, 'Generic qualitative research in psychology', The Qualitative Report 20(2), 76-85. https://doi.org/10.46743/2160psychology', The
$3715 / 2015.2097$

Polit, D.F. \& Beck, C.T., 2012, Nursing research: Generating and assessing evidence for nursing practice, 9th edn., Wolters Kluwer Health | Lippincott Williams \& Wilkins, Philadelphia, PA.
Porterfield, T.E., Macdonald, J.R. \& Griffis, S.E., 2012, 'An exploration of the relational effects of supply chain disruptions', Transportation Journal 51(4), 399-427. https://doi.org/10.5325/transportationj.51.4.0399

Prajogo, D. \& Olhager, J., 2012, 'Supply chain integration and performance: The effects of long-term relationships, information technology and sharing, and logistics integration', International Journal of Production Economics 135(1), 514-522. https://doi.org/10.1016/j.ijpe.2011.09.001

Qi, Y. \& Zhang, Q., 2008, 'Research on information sharing risk in supply chain management', 4th International Conference on Wireless Communications, Networking and Mobile Computing, Dalian, China, 12-14 Oct, 2008, pp. 1-6. doi: 10.1109/ WiCom.2008.1618. https://ieeexplore.ieee.org/abstract/document/4679526

Rajagopal, V., Venkatesan, S.P. \& Goh, M., 2017, 'Decision-making models for supply chain risk mitigation: A review', Computers \& Industrial Engineering 113, 646-682. https://doi.org/10.1016/j.cie.2017.09.043

Rood, C., Van den Berg, D., Niemann, W. \& Meyer, A., 2018, 'The role of personal relationships in supply chain disruptions: Perspectives from buyers and suppliers of logistics services', Acta Commercii 18(1), 1-15. https://doi.org/10.4102/ac.v18i1.608

Sandelowski, M., 2000, 'Whatever happened to qualitative description?', Research in Nursing \& Health 23(4), 334-340. https://doi.org/10.1002/1098240X(200008)23:4\%3C334::AID-NUR9\%3E3.0.CO;2-G

Shenton, A.K., 2004, 'Strategies for ensuring trustworthiness in qualitative research projects', Education for Information 22(2), 63-75. https://doi.org/10.3233/EFI2004-22201

Skinner, D., Dietz, G. \& Weibel, A., 2014, 'The dark side of trust: When trust becomes a "poisoned chalice", Organization 21(2), 206-224. https://doi. org $/ 10.1177 / 1350508412473866$

Tan, K.H., Wong, W. \& Chung, L., 2016, 'Information and knowledge leakage in supply chain', Information Systems Frontiers 18(3), 621-638. https://doi.org/10.1007/ s10796-015-9553-6

Vaidya, O. \& Hudnurkar, M., 2013, 'Multi-criteria supply chain performance evaluation An Indian chemical industry case study', International Journal of Productivity and Performance Management org/10.1108/17410401311309195

Van Riper, C.J., Wallen, K.E., Landon, A.C., Petriello, M.A., Kyle, G.T. \& Absher, J., 2016 'Modeling the trust-risk relationship in a wildland recreation setting: A socia exchange perspective', Journal of Outdoor Recreation and Tourism 13, 23-33. https://doi.org/10.1016/j.jort.2016.03.001

Vermeulen, Y., Niemann, W. \& Kotzé, T., 2016, 'Supply chain integration: A qualitative exploration of perspectives from plastic manufacturers in Gauteng', Journal of Transport and Supply Chain Management 10(1), 1-13. https://doi.org/10.4102/ jtscm.v10i1.223

Wang, B., Childerhouse, P., Kang, Y., Huo, B. \& Mathrani, S, 2016, 'Enablers of supply chain integration: Interpersonal and interorganizational relationship perspectives' Industrial Management \& Data Systems 116(4), 838-855. https://doi org/10.1108/IMDS-09-2015-0403

Wang, Z., Ye, F. \& Tan, K.H., 2014, 'Effects of managerial ties and trust on supply chain information sharing and supplier opportunism', International Journal of Production Research 52(23), 7046-7061. https://doi.org/10.1080/00207543.201 4.932931

Wieland, A. \& Wallenburg C.M., 2013, 'The influence of relational competencies on supply chain resilience: A relational view', International Journal of Physical supply chain resilience: A relational view', International Journal of Physical
Distribution \& Logistics Management 43(4), 300-320. https://doi.org/10.1108/ Distribution \& Logistics
IJPDLM-08-2012-0243

Zacharia, Z.G., Sanders, N.R. \& Nix, N.W., 2011, 'The emerging role of the third-party logistics provider (3PL) as an orchestrator', Journal of Business Logistics 32(1), 40-54. https://doi.org/10.1111/j.2158-1592.2011.01004.x

Zhang, D.Y., Cao, X., Wang, L. \& Zeng, Y. 2012. 'Mitigating the risk of information leakage in a two-level supply chain through optimal supplier selection', Journal of Intelligent Manufacturing 23(4), 1351-1364. https://doi.org/10.1007/s10845-011-0527-3

Zhou, K.Z., Zhang, Q., Sheng, S., Xie, E. \& Bao, Y., 2014, 'Are relational ties always good for knowledge acquisition? Buyer-supplier exchanges in China', Journal of Operations Management 32(3), 88-98. https://doi.org/10.1016/j.jom.2014.01.001 